\title{
ABSTRACTS FROM CURRENT LITERATURE
}

\section{Is Articular Rheumatism an Allergic Condition ? Herman Kirschhof. (From the Medical Clinic of the University of Munich.) Zeitschrift für Rheumaforschung, September, 1938, Band I., Heft 9, p. 302.}

The author reviews the conclusions of many authorities upon this question and reports the results of experiments he has carried out to elucidate the problem. Aschoff, Gräff and Fahr think that articular rheumatism is a specific infection, though the exciting agent has not yet been discovered. In contrast with this view Klinge and Rössle think that the so-called fibrinoid degeneration is due to an allergic reaction. Rössle limits his opinion in this respect to acute articular rheumatism, whereas Klinge includes the chronic forms of arthritis, muscular rheumatism, gout and neuralgias. Klinge thinks that bacterial proteins are the allergic factor, but Gudzent considers they probably derive from decomposed foods and from proteins of animal and vegetable origin. These authors attach the term "visceral rheumatism" to many disorders of the heart, the pleura, the joints, arteries and veins. Kämmerer regards allergy as partly inborn, partly acquired specific reactivity to certain substances which are harmless to the normal person. Berger regards allergy as an antibody diathesis, using the term "diathesis" as a symptomless state in which the body is ready to react. An allergic disease may thus be regarded as an interaction between allergens and the antibody reaction. Gudzent bases his views on the results of skin tests; in 10 per cent. of non-rheumatic persons positive reactions occurred, and these he regards as due to a latent rheumatic state. The author has carried out experiments using allergenine, which is prepared from certain protein solutions. Out of 60 cases of acute and chronic arthritis, in 19 only was an unequivocal result obtained, and of these 11 gave negative results. $\mathrm{He}$ reports that his experiments have been repeated by others in 230 cases, with similar results. He also tested a series of patients suffering from diseases other than rheumatism, and out of 48 persons 39 gave positive results. He draws the conclusion on 
grounds which are fully set out that there is no difference between the reactions of rheumatic cases and others. Experiments carried out to judge the value of skin tests showed that they diminished with age, though the general sensitivity might increase, and the conclusion was drawn that Gudzent's reactions are essentially physiological and resemble the phenomena of Storm van Leeuwen. Allergic conditions can often be identified best from the presence of eosinophilia, which was present in 11 to 17 per cent. of the author's cases.

The author draws the conclusion that Aschoff's view is supported by the high fever, the sedimentation rate, leucocytosis, frequent preceding sore throat and other infections, and the occasional benefit from tonsillectomy. Negative findings do not exclude the virus infections. He does not accept any generally aller gic origin of acute or chronic rheumatic conditions.

C. W. B.

Prevention and Treatment of Catarrhal Rheumatism. Professor K. von Neergard (Zurich). Zeitschrift für Rheumaforschung, October, 1938, Band I., Heft 10.

The author contends that the great mass of the rheumatic infections are secondary or tertiary manifestations of invasion by the filtrable virus of the common cold, which was first identified by Kruse and named by him the aphanazon; further light has been thrown upon it by the experiments of Dochez and others. Without stressing the diagnostic differences between rheumatism of catarrhal origin and that due to coccal invasion, the author believes that the latter forms less than 10 per cent. of the whole. The effect of dealing with septic foci has, he thinks, been overstressed, and that many transient improvements after treatment of teeth or tonsils may be attributed to the non-specific stimulation of the operation.

Prophylactic moasures should be directed to the raising of resistance. It is known that this quality is greater and more lasting if an acute infection has just passed; abortive attacks may even harm the patient, as for instance when, in the popular phrase, the cold "has not come out properly." It is suggested that the aim, therefore, ought not to be to diminish the severity of any catarrhal attack on this account. It appears likely that attendance at public functions and the numerous social contacts bring about an increase in chronic disease. Neufeld holds that the 
repeated small infections arising from these are more lowering than occasional massive invasions.

The author advocates a policy of prophylaxis by measures directed to raising the resistance to such infections. The individual must be trained to changes of temperature by the application of alternate cold and heat to develop the reactive capacity of the body, but gradual and insidious chilling must be avoided. Such a hardening process may be carefully carried out in the open air. He advocates a popular campaign by means of pamphlets, etc., warning against damp houses, unsuitable food, bad teeth, etc. While advising open-air exercise, he warns against excessive sun-bathing. He condemns central heating and excessive sporting activity.

The views expressed in a long article frequently run counter to generally accepted ideas, but are worthy of careful consideration, especially by those interested in the social aspects of the rheumatism campaign.

C. W. B.

\section{Pathogenic Pleuropneumonia-tike Micro-Organisms from} acute Rheumatic Exudates and Tissues. Homer F. Swift and T. McPherson Brown. Science, March 24, 1939, vol. Ixxxix., p. 271.

This contribution strikes a new and hopeful note in the search for a specific infective agent in acute rheumatism. The work consisted of several stages. (1) Exudates from acute cases, after three to five passages on the chorio-allantoic membrane of the chick, have been found to produce characteristic lesions in it, described as structures surrounded by flattened epithelium, and containing in their centre condensed eosinophilic material and varying amounts of inflammatory reaction. The agent giving rise to these changes passes through a Berkefeld filter. (2) By inoculating mice intranasally with suspensions of these chick membranes, or with the filtrate, a pneumonic disease was induced that is also transmissible in series and filterable. (3) After a few subcultures in beef-serum-dextrose-broth, or on solid media rich in serum, pleuropneumonia-like organisms were grown alike from the affected chick membranes or from suspensions of the lungs of affected mice. (4) At this point an attempt was made to culture in the same way, and using the same repeated passage technique, rheumatic joint fluid and an excised erythema nodosum nodule, with the result that pleuropneumonia-like organisms were grown 
from both. These cultures were then found to produce in mice the same type of pneumonia that had been produced by infecting them with the chick membrane cultures. Thus, it was possible to cultivate on cell-free media pleuropneumonia-like organisms from exudates of patients with rheumatic fever, from chick membranes inoculated therewith, and from the lungs of mice inoculated with either. This success seems to have been due chiefly to the repeated passage technique alike in the animals and in the media used. Further reports of this new and promising work will be awaited with interest. Although the authors rightly decline to pronounce on the ætiological significance of their results at the present stage, it would seem likely that the question of the presence of specific antibody in the serum of patients may be helpful on that matter.

M. H. G. 